\title{
Identifying Treatment and Healthcare Seeking Behavior as a Means of Early HIV/AIDS Intervention in Africa
}

\author{
Henry Fomundam $^{1 *}$, Abraham Tesfay ${ }^{1}$, Andrew Maranga $^{2}$, Lucia Chanetsa $^{1}$, Vieira Muzoola $^{3}$, \\ Frederick Oyaro ${ }^{4}$
}

${ }^{1}$ Howard University HIV and AIDS Pharmaceutical Care Program, Regional Office, Pretoria, South Africa; ${ }^{2}$ Howard University HIV and AIDS Pharmaceutical Care Program, East Africa-Nairobi, Kenya Office, Nairobi, Kenya; ${ }^{3}$ Howard University HIV and AIDS Pharmaceutical Care Program, Kigali, Rwanda; ${ }^{4}$ Howard University HIV and AIDS Pharmaceutical Care Program, Dar es Salaam, Tanzania.

Email: *hfomundam@aol.com

Received September $6^{\text {th }}, 2011$; revised November $16^{\text {th }}, 2011$; accepted July $18^{\text {th }}, 2012$

\begin{abstract}
Background: Late diagnosis of Human Immunodeficiency Virus (HIV) infection and delayed commencement of antiretroviral therapy (ART) in sub-Saharan Africa is known to contribute to high morbidity and mortality. It is therefore, prudent to develop innovative approaches to ensure early HIV diagnosis because patients with low immunity will usually develop opportunistic infections and seek some remedial action. A treatment and health care seeking behavior survey was carried out in semi-urban communities in Malaba and Busia in Kenya and Uganda to evaluate the treatment and healthcare seeking behavior among patients visiting randomly selected drugstores. Methodology: Random sampling was applied and questionnaires were used to collect information from 165 interviewees who visited drugstores seeking health information, treatment and other health related services. Results: The results indicated that among this group of people, $67 \%$ visited drugstores before any other health facility. $72.2 \%$ sought treatment for various illnesses and services ranging from headaches, body fever, gastro-intestinal disturbances, family planning pills, sexually transmitted infections and chronic medications. Among the patients interviewed, there were a number of factors that affected treatment choice. These included the distance to the facility as well as the absence of a consultation fee or fee for service. Conclusion: With proper support, drugstores can play a major role in the implementation of health interventions that seek to promote early diagnosis and treatment as well as play a pivotal role in educating the population on disease prevention and management. In Sub-Saharan Africa, drugstores can play a major role in HIV and AIDS interventions where most patients seek medical intervention for opportunistic infection.
\end{abstract}

Keywords: Treatment and Health Seeking Behavior; Drug Stores

\section{Background}

\subsection{Treatment and Healthcare Seeking Behaviour}

Treatment seeking behaviour can be used as an indicator of a patient's willingness to preserve life, and is crucial to personal, societal and national development [1]. In this survey treatment seeking behavior refers to "the sequence of remedial actions that individuals undertake to rectify perceived 'ill health'. It is initiated with symptom definition where a strategy for treatment action is devised [2]. Illness or deviation from state of health is usually a subjective phenomenon, the relief of which may be sought within or outside of health facilities [3].

Perception of illness has been found to vary with cultural, ethnic and socioeconomic differences. As a result,

"Corresponding author. treatment-seeking behaviour may be influenced by cultural beliefs about the cause and cure of illness. For efficient disease control and management, the individual and community's treatment seeking behaviour needs to be understood as it influences the duration of symptoms and the probability of morbidity and harmful sequelae [1].

The choice of treatment source can be influenced by various factors. These include accessibility, type of illness and its severity, as well as the individual's level of education [4]. The level of education can be used to predict health seeking behaviour as a higher level of education is often associated with exposure to scientific knowledge and practice [5]. User fees for services have also played a role in influencing treatment seeking behavior in patients; exemption from user fees has been associated with increase health services utilization, early treatment-seeking and thereby promote early diagnosis 
and treatment [6]. A study in a developing country found increased willingness to be on antiretroviral therapy (ART), but a substantially lower willingness to pay for it. Income and illness had a significant positive relationship with the willingness to pay [7].

In its varying forms, ill-health has been found to have a significant impact on a community's social, cultural and economic standing. It has a direct economic effect on households through diversion of family income towards treatment and indirectly by reducing productivity and thereby contributing to a decline in household welfare [8]. Early diagnosis and appropriate treatment are essential in preventing and reducing morbidity and mortality [4]. At the broader community level, ill-health also means less time on the job; lowered production and productivity; reduced Gross Domestic Product (GDP) and savings for a country; high expenditure on healthcare; diversion of resources from education and other social priorities to health care. This can further increase poverty; negatively impacting on poverty alleviation efforts. Health, therefore, holds a key to social and economic development [1].

Understanding human treatment seeking behavior is essential in changing behavior and improving health practices. Experts in health interventions and policy have become increasingly aware of the influence of human behavioral factors in quality health care provision and uptake. In order to respond to community perspectives and needs on diseases of public health importance, health systems need to adapt their strategies, taking into account the findings from behavioral studies [9]. Lifestyle and behavioral change in the treatment seeking pattern can be influenced through a combination of learning experiences that enhance awareness, increase motivation and build skills. It is also important to create an environment that makes positive health practices the easier and more preferred choice [10].

In any health program, understanding the treatment seeking behavior of the target community will help in the design and implementation of interventions that seek to promote early diagnosis and treatment; help educate the population on the importance of disease prevention and correct management; help identify and target facilities for capacity building (human and infrastructural); and identify convenient sites for recruiting patients. Knowing a community's first treatment option will also help create and strengthen a resource in the community that can be used as a patient recruitment and referral point for the more established and specialized health centers.

\subsection{HIV/AIDS, Pharmaceutical Care, and Human Resources Challenges in Sub-Saharan Africa}

The 1978 Declaration of Alma Ata issued an urgent call for the world's nations to focus on primary healthcare
(Alma-Ata, WHO, 1978). Sub-Saharan African (SSA) countries have had many challenges in increasing access to universal primary healthcare and the provision of essential medicines [11]. These countries have major human resource challenges with a large patient to health service provider ratio despite accounting for a significant global burden of disease [12]. As at the end of 2009, there were an estimated 22.5 million people living with HIV in sub-Saharan, including 2.3 million children [13]. During the same year, an estimated 1.3 million Africans died from AIDS-related illness with almost $90 \%$ of the 16.6 million children orphaned by AIDS living in subSaharan Africa.

At the end of 2009, there were an estimated 1.5 million and 1.2 million people living with HIV in Kenya and Uganda respectively. Although there has been a major effort to scale up access to HIV treatment, a significant number of people living with HIV (PLHIV) who are eligible for HIV treatment still lack access [13,14].

The overall goal of ART is to reduce HIV-related morbidity and mortality as well as improve the quality of life of the patient. This is achieved through maximal and sustained suppression of viral load, preservation or restoration of the immune function, and prevention of opportunistic infections. Recently, the benefits of ART have been seen in HIV prevention where ART has been successfully used in prevention of mother-to-child transmission (PMTCT) while the HIV Prevention Trials Network Study (HPTN Study 052) reported that initiation of ART protects the uninfected sexual partner from HIV infection [15]. There is however a challenge in provision of ART where most patients present for health care at late stages of the disease with severe immunosuppression and thereby reducing the benefits of therapy and immune recovery [16].

Through understanding a community's treatment seeking behavior, first line health personnel can be utilized and strengthened to promote early HIV diagnosis and prompt timely initiation of ART according to the eligibility criteria. These health workers can also be used as a platform for mobilizing and educating the public on key healthcare issues.

According to the Commission for Africa (2005), SSA suffers from $25 \%$ of the world's disease burden but has only $1.3 \%$ of the world's health workforce [17]. Comparisons to developed countries are striking; the World Health Organization (WHO) guidelines recommend a ratio of 2300 persons to 1 pharmacist. Japan has 22.1 pharmacists per 23,000 , France 14.3 per 23,000 , Australia 10.14 per 23,000 , and USA 8.58 per 23,000. Liberia, for example, has just 1 pharmacist per 120,076 people [17]. Such a large disease burden and shortage of health personnel puts considerable strain on the available health workers and the health system. The disparities between 
the developed and the developing countries are outlined in the table below (Table 1).

Recent estimates of the total population of Kenya put it at a total population of 39.4 million (2009 estimates) with a gross national income per capita of US\$1470 and a life expectancy of 58.9 years [18]. Infectious diseases that can be easily controlled and managed, continue to be a problem in the country; responsible for a significant level of morbidity and mortality. In 2009 the WHO national statistics showed that, 106,438 people suffered from new and relapse cases of TB with 24,435 recorded deaths from TB in 2007.

Uganda, which shares its eastern border with Kenya, has a population of $29,899,000$ and a gross national income per capita of US\$880. The life expectancy is 51 years [7]. In 2007 there were 28,686 recorded deaths as a result of Tuberculosis while in 2009, about 40,909 cases of new and relapse TB cases were reported. According to the WHO 2004 data, the number one cause of death in developing countries was lower respiratory infections; conditions that can be easily managed through early diagnosis and appropriate drug therapy [19].

With such a large disease burden and the poor health care infrastructure, patients often find themselves with limited options for treatment. It has been observed in some communities that although western medical concepts have been assimilated, many patients subscribe to both traditional and western medical paradigms as a result of their traditional understanding of illness [20]. According to Matowe et al., the shortage of pharmacists deprives the population of vital expertise in the management of drug related problems in both the community and hospital settings [21]. As a result, clients make costly visits to hospitals staffed by overstretched nurses, doctors, and other staff further burdening an already overwhelmed system [22]. Because of the increased need for health care services, an array of healthcare professionals, allied healthcare workers and others have been known to acquire, dispense, and in some cases administer medicines [17]. This shift in health care personnel availability and accessibility is therefore likely to influence treatment seeking practices in the two countries as well as in many other sub-Saharan African countries.

In Uganda, as is the case in a number of African countries, there are more traditional medicine healers than pharmacists and pharmaceutical care personnel put together. Table 2 summarizes the population to health care professional ratios across various African countries to highlight the severe shortages of health care professionals as well as the skewed distribution between urban and rural communities.

\section{Methodology}

\subsection{Project Setting}

This survey was conducted in Busia and Malaba, two cross-border towns on the common borders of Kenya and Uganda. These two towns are the busiest crossing points on this common border and provide transit points for people and goods to Uganda as well as to several other East and Central African countries (Rwanda, Burundi, South Sudan and the Eastern parts of The Democratic Republic of Congo).

Like in many East African countries, the health care sectors of both Busia and Malaba are populated by small pharmacies and drug shops that serve the health care needs of the population. These drugs hops may be up to fifteen times more in number than the retail pharmacies. For the purpose of this write up a drug shop is a facility that stocks prescription and non-prescription medicines that is run by a lower-cadre health worker and may or may not be registered. Table 3 outlines the numbers of retail pharmacies and drug shops in Kenya, Tanzania and Uganda.

Table 1. Comparative pharmacist workload for the HIV population for some European and SAA countries.

\begin{tabular}{|c|c|c|c|c|c|}
\hline Country & Population & Infected Adults & $\begin{array}{c}\text { Infected Adults } \\
\text { (Total Population Rate in \%) }\end{array}$ & $\begin{array}{l}\text { Infected Adults } \\
\text { (Adult Rate in \%) }\end{array}$ & $\begin{array}{c}\text { Infected Persons } \\
\text { per Pharmacist }\end{array}$ \\
\hline France & $60,140,000$ & 120,000 & 0.20 & 0.40 & 2 \\
\hline Denmark & $5,360,000$ & 5000 & 0.09 & 0.20 & 5 \\
\hline Senegal & $10,000,000$ & 41,000 & 0.44 & 0.80 & 62 \\
\hline Central African Rep. & $3,800,000$ & 240,000 & 6.73 & 13.50 & 223 \\
\hline Kenya & $32,000,000$ & $1,110,000$ & 3.75 & 6.70 & 625 \\
\hline Botswana & $1,785,000$ & 330,000 & 19.61 & 37.30 & 1320 \\
\hline
\end{tabular}


Table 2. SSA pharmacy personnel and population ratios ${ }^{\sharp}[18]$.

\begin{tabular}{|c|c|c|c|c|c|c|}
\hline $\begin{array}{l}\text { Name of } \\
\text { Country }\end{array}$ & $\begin{array}{l}\text { Number of } \\
\text { Pharmacists }\end{array}$ & $\begin{array}{l}\text { Population per } \\
\text { Pharmacist }^{\ddagger}\end{array}$ & $\begin{array}{c}\text { Number of } \\
\text { Pharmacists in } \\
\text { Rural/Urban Area }\end{array}$ & $\begin{array}{c}\text { Has Formal } \\
\text { Pharmacy } \\
\text { Technician Training }\end{array}$ & $\begin{array}{c}\text { Number of } \\
\text { Pharmacy } \\
\text { Technicians/Assistants }\end{array}$ & $\begin{array}{c}\text { Total Number of } \\
\text { Pharmacists and } \\
\text { Technicians }{ }^{\bar{\top}} \\
\end{array}$ \\
\hline Angola & 24 & 466,283 & $* / *$ & $*$ & $*$ & $*$ \\
\hline Benin & 11 & 678,184 & $0 / 11$ & $*$ & $*$ & * \\
\hline Botswana & 140 & 11,715 & $* / *$ & Yes & 193 & 333 \\
\hline Burkina Faso & 70 & 198,933 & $* / *$ & * & 116 & 343 \\
\hline Burundi & 73 & 87,269 & $0 / 73$ & $*$ & 3 & 76 \\
\hline Cameroon & 950 & 23,400 & $70 / 630$ & $*$ & $*$ & $*$ \\
\hline Chad & 31 & 316,981 & $5 / 26$ & * & 6 & 37 \\
\hline $\mathrm{DRC}$ & 1200 & 53,046 & $360 / 840$ & $*$ & $*$ & * \\
\hline Equat. Guinea & 12 & 44,657 & $0 / 12$ & $*$ & 109 & 121 \\
\hline Gabon & 33 & 42,097 & $0 / 33$ & * & 30 & 63 \\
\hline Ghana & 1388 & 15,151 & $* / *$ & Yes & 1388 & 2162 \\
\hline Guinea & 475 & 17,864 & $36 / 439$ & $*$ & 55 & 530 \\
\hline Kenya & 1861 & 18,178 & $* / *$ & Yes & 1321 & 1342 \\
\hline Lesotho & 17 & 109,826 & $* / *$ & Yes & * & $*$ \\
\hline Liberia & 29 & 120,076 & $1 / 28$ & $*$ & 6 & 35 \\
\hline Malawi & 37 & 328,620 & $* / *$ & $*$ & $*$ & $*$ \\
\hline Mali & 320 & 38,411 & $0 / 351$ & $*$ & $*$ & $*$ \\
\hline Mozambique & 14 & 1386 & $* / *$ & $*$ & 604 & 618 \\
\hline Namibia & 201 & 10,103 & $* / *$ & Yes & 94 & 288 \\
\hline Niger & 20 & 583,297 & $2 / 18$ & * & * & $*$ \\
\hline Nigeria & 8642 & 14,901 & $* / *$ & Yes & $*$ & $*$ \\
\hline Rwanda & 12 & 75,364 & $0 / 112$ & Yes & 166 & 278 \\
\hline Senegal & 63 & 176,616 & $8 / *$ & * & 22 & 85 \\
\hline Sierra Leone & 84 & 71,639 & $* / *$ & $*$ & 256 & 340 \\
\hline South Africa & 11,097 & 3996 & $* / *$ & Yes & 1424 & 12,521 \\
\hline Swaziland & 46 & 25,520 & $0 / 46$ & * & 24 & 70 \\
\hline Tanzania & 368 & 100,730 & $* / *$ & * & $*$ & $*$ \\
\hline Togo & 49 & 115,949 & $21 / 28$ & $*$ & 85 & 134 \\
\hline Uganda & 215 & 126,835 & $9 / 206$ & * & 473 & 249 \\
\hline Zambia & 68 & 165,615 & $* / *$ & * & 332 & 1039 \\
\hline Zimbabwe & 605 & 21,069 & $* / *$ & Yes & 278 & 883 \\
\hline
\end{tabular}

High health worker mobility and poor record keeping make it challenging to report accurate numbers; these are estimates from various reference sources. \#Global Pharmacy Workforce and Migration Report (FIP, 2005); Lockwood, 2005; International Pharmaceutical Federation et al., 2006; WHO 2006; WHO/AFRO, 2006a, 2006b, 2006c, 2006d, 2006e, 2006f, 2006g, 2006h, 2006i, 2006j, 2006k, 20061; Losse et al., 2007; International Pharmaceutical Federation (FIP, 2007a); International Pharmaceutical Federation (FIP, 2007b); *No data available; ${ }^{*}$ WHO guidelines recommend 1 pharmacist per population of 2300, WHO Global Atlas, 2006; ``WHO AFRO, 2006.

Table 3. Pharmacies and drug shops.

\begin{tabular}{ccc}
\hline Country & No of Pharmacies (Retail) & No of Drug Shops \\
\hline Tanzania & 780 & 11,800 \\
Kenya & 1250 & $*$ \\
Uganda & 490 & 5200 \\
\hline
\end{tabular}




\subsubsection{Study Design}

A cross sectional descriptive study design was used to describe treatment seeking behaviors of clients who visit drug stores.

\subsubsection{Data Collection and Analysis}

Data was collected from randomly selected drug stores. The questionnaire was administered by the drug store operators and was designed to collect information pertaining to the preferred treatment option, factors that influence treatment choices, educational background of the patients, symptoms most commonly reported and the medication treatment seeking patterns. Patients were also asked to rank common reasons for selecting treatment facilities in order of popularity. Epi-info ${ }^{\circledR}$ statistical software was used for data management and analysis.

\section{Results}

Data from this survey were analyzed according to patient demographics, reasons for seeking treatment, first treatment option as well as common reasons given by patients for choosing health care providers. A total of 165 drug shop clients were interviewed. Sixty one percent (97) of the interviewees were female and 39\% (62) were male. The mean age of the female interviewees was 32.1 years and 32.7 for males. In terms of patients' treatment preferences, $67 \%(n=165)$ consulted drug store personnel as their first treatment option. $33 \%$ of the patients had consulted other drug store facilities before coming into the drug stores where the survey was conducted. Some patients had consulted more than one facility for the very same condition, $20 \%$ (of the 165 patients that participated in the survey) had first been to a clinic or hospital, $5 \%$ had been to a pharmacy, and $8 \%$ had first sought help from a traditional healer (Figure 1).

Patients who had sought treatment from other facilities before coming into the drug stores came in either because there was no response to treatment $(39 \% \mathrm{n}=65)$ or because the condition had worsened $(53 \% \mathrm{n}=88)$.

About 7.5\% (12) had never been to school; 37.7\% (60) had attained a primary school level education. About $28 \%(n=159)$ of the drug store interviewees had a tertiary-level qualification. The level of academic qualification of the interviewees can be seen in Figure 2.

With regards to the reasons and time of visiting the drug store, $72.2 \%$ of patients interviewed $(\mathrm{N}=165)$ reported that the main reason for visiting the drug store was because they were "sick". The most common presenting symptom were headaches $(40.6 \%, \mathrm{~N}=165)$ followed by recurrent fevers and sweats $(33.3 \%, \mathrm{~N}=165)$. Fifty-nine patients $(35.8 \%, \mathrm{~N}=165)$ came in for family planning services and advice on condom use. Fifteen point four $(15.4 \%, \mathrm{~N}=165)$ of the patients complained of recurrent diarrhea, $15.4 \%$ of genital discharge and $11.5 \%$ of genital pain. Eighteen of the patients suffering from recurrent fever only consulted the drug stores after at least five days of being sick. The diseases and symptoms presented by the patients on contact with the drug store are summarized in Table 4.
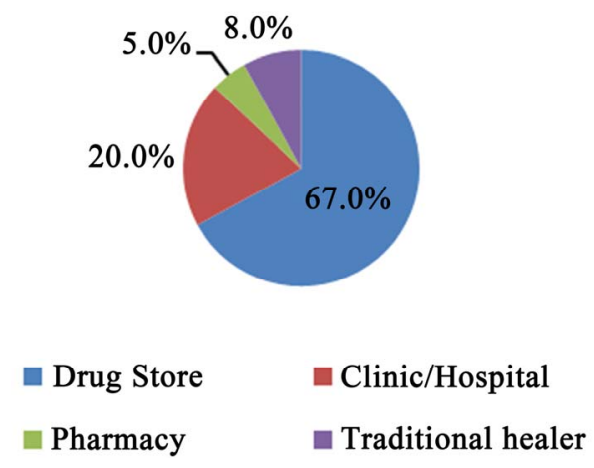

Figure 1. First treatment option.

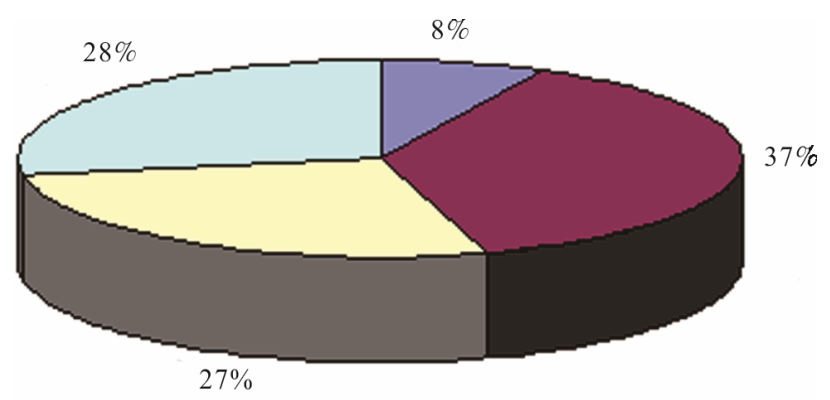

$\square$ No formal education $\boldsymbol{\square}$ Primary school $\square$ Second school $\square$ Tertiary

Figure 2. Educational qualification of interviewees $(n=165)$.

Table 4. Symptoms patients presented with upon arrival to the facilities.

\begin{tabular}{lcc}
\hline \multicolumn{1}{c}{ Reason given } & $\begin{array}{c}\text { Number of } \\
\text { respondents }\end{array}$ & Percentage \\
\hline Headache & 67 & $40.6 \%$ \\
Family planning & 59 & $35.8 \%$ \\
Recurrent fever/sweating & 55 & $33.3 \%$ \\
Persistent cough & 27 & $16.4 \%$ \\
Recurrent diarrhea & 26 & $15.8 \%$ \\
Genital discharge & 26 & $15.8 \%$ \\
Skin condition & 25 & $15.2 \%$ \\
Genital lesions/sores & 22 & $13.3 \%$ \\
Rapid weight loss & 19 & $11.5 \%$ \\
Pelvic/Genital pain & 19 & $11.5 \%$ \\
HIV and AIDS medication & 19 & $11.5 \%$ \\
Chronic conditions & 18 & $10.9 \%$ \\
White spots in the mouth & 12 & $7.3 \%$ \\
Swollen lymph nodes & 5 & $3.0 \%$ \\
Diagnosed TB patients & 5 & $3.0 \%$ \\
Total & 165 & $100 \%$ \\
\hline
\end{tabular}


At the time of visiting the drug stores, $35.8 \%$ of the patients had been sick for 2 - 4 days, $15.8 \%$ had been sick for 5 - 10 days while $14.5 \%$ had been sick for up to two weeks. Clients who came in for family planning and for chronic medication refills accounted for $7.3 \%$ and $12.1 \%$ of the patients respectively. The number of days that people waited before seeking treatment for their condition is illustrated in Table 5.

The use of both traditional and western medicine, although practiced at a smaller scale, is still an important factor in treatment. Although only $8 \%$ of the interviewed patients reported having first gone to a traditional healer, $41.25 \%$ of 165 interviewees reported having previously used traditional medicines for various conditions. $20 \%$ admitted having taken traditional medicines concurrently with conventional pharmaceuticals. There was no apparent direct relationship between educational level and the use of traditional medicines. Of the 62 patients who reported having used traditional medicines, $30.6 \%$ of the patients had a tertiary-level qualification, $30.6 \%$ had a secondary school qualification, $30.6 \%$ had a primary school qualification and $8 \%$ had had no formal education.

The patients reported various reasons for choosing the facility over others. $24.3 \%$ reported that it was because of the distance to the facility; $21.2 \%$ for quality and availability of service; $12.6 \%$ for absence of user fees; $10 \%$ on attitude of health personnel towards patients; $9.5 \%$ availability of drugs; $9.2 \%$ easy access to health care personnel; $6.7 \%$ privacy and confidentiality; $4.5 \%$ availability of other services and $1.9 \%$ the speed of service delivery.

\section{Discussion}

In most SSA countries, the governments are largely responsible for provision of healthcare to the population [23]. However, universal access to health remains a great challenge mainly driven by a severe shortage of health personnel and poorly developed health infrastructure [24]. Even where there are some available health services, the distribution is usually skewed towards urban areas [25].

Table 5. Duration of sickness before seeking treatment.

\begin{tabular}{ccc}
\hline Days while sick & Number of respondent & Percent \\
\hline 1 day & 10 & $6.1 \%$ \\
2 - 4 days & 59 & $35.8 \%$ \\
5 - 10 days & 26 & $15.8 \%$ \\
10 - 14 days & 24 & $14.5 \%$ \\
Chronic condition & 20 & $12.1 \%$ \\
Family planning & 12 & $7.3 \%$ \\
Not specified & 14 & $8.5 \%$ \\
Total & 165 & $100.00 \%$ \\
\hline
\end{tabular}

The HIV epidemic has had a significant impact on the health systems and its capacity to provide healthcare to the population [26]. HIV infected individuals are more likely to suffer from infectious diseases by virtue of the compromised immunity and therefore require more frequent medical attention in the health facilities. This ultimately increases patient volumes and thereby overwhelming the few available health workers. Secondly, there is the direct impact on the health worker who gets infected and leading to reduced ability to discharge their roles and ultimately loss through death [27].

Additionally, there is an increasing demand for resources to train health workers since additional skills and capacity is consistently required to ensure continued quality of care [28]. All these facts contribute to long queues and waiting times at most clinics and hospitals.

The results of the survey present several interesting insights on the treatment seeking behavior of individuals in the study community. The community drugstores are a major source of healthcare in rural and peri-urban communities. Of the 165 individuals participating in the survey $67 \%$ reported visiting the drugstore as the first point of call. The survey also revealed that there were other reasons for visiting the drugstores beyond illness. It was reported that $17.8 \%$ of the respondents had visited the drugstore for information and supply of family planning methods as well as purchase of condoms. This indicates that drugstores can play an important role in dissemination of information on issues of public health concern in the community.

\subsection{Gender and Treatment Seeking Behavior}

The survey showed that there was utilization of services in the drugstores by community members from both genders although there were higher numbers of females participating in the survey. A population-based study conducted in Nairobi, Kenya showed major gender differences in proportions seeking care for STIs and that majority of men and women sought STI care in private health facilities including community pharmacies [29]. These findings illustrate the important role that private facilities play in the provision of health care in many African communities. There have however been questions about the quality of services available in these facilities despite perception of high quality among their clients [30]. It is therefore important to put in place mechanisms to improve the quality and appropriateness of services.

\subsection{Influence of Level of Education on Treatment Seeking}

The findings of the survey indicated that the patients visiting drugstores had varied levels of education ranging 
from no formal education to tertiary level. The level of education did not seem to affect utilization of traditional medicines. However, some studies have reported an increase in utilization of western medicines and improved health with increasing maternal education [31,32]. Drugstores, by virtue of serving a significant portion of the population, present a major opportunity to increase access to health information. However, taking into consideration the varied levels of education of the clientele, it is important that materials and information provided be easily understood irrespective of the level of education and the language used.

\subsection{Reasons for Visiting}

The patients/clients visiting the drugstores presented with various reasons for visiting the facility. These services include treatment for minor ailments, family planning, recurrent fever, sexually transmitted infections (STI), diarrhea and respiratory tract infections. This clearly indicates that the patients expect to receive a range of services comparable to what is available in the public facilities. However, these drugstores are not mandated by law to provide the whole range of services [33]. To ensure that the patients access quality and appropriate information and services from drug stores, it is important that the drugstore personnel recognize their limitations in terms of skills and knowledge and have mechanisms that can facilitate referral for more specialized services. Additionally, the range of services allowed in these facilities should be reviewed and appropriate training provided.

\subsection{Why Preference for Drugstores}

The findings of the survey indicated several reasons why the patients visited the drugstores for health services and the reasons for the preference [34]. Closer proximity of the drug store seemed to be the major consideration for opting to seek health services from these facilities. Other reasons included perceptions of better quality and availability of services, more friendly health providers, availability of medicines, better privacy and confidentiality, and faster services.

Several studies have demonstrated that individuals prefer use of private health institutions including drug stores for various health services through self-medication and consultation with the drugstore personnel. Some of the services sought in the drugstores include treatment for sexually transmitted diseases, family planning [35], malaria treatment [36], childhood diseases (including diarrhea and acute respiratory infections) [36]. This indicates that there are a lot of health issues that drug store operators are presented with as they do business and interact with the community. However, it is doubtful that these drugstore personnel have the necessary skills and knowledge to effectively provide these services.

\section{Study Limitations}

The survey does not represent a random sample of patients in the community consulting all the health care facilities. The questionnaire was administered to patients who came into the drug shop only.

\section{Conclusions}

From the survey and other published literature, it is evident that drugstores are a major contributor to healthcare for the population in Sub-Saharan Africa. Although the quality of service may not be optimal, these cadres of health care workers can be properly trained and integrated in disease prevention and management strategies.

If properly managed and supported, drug store personnel can play an important part in dissemination of important health information and increase access to and utilization of services for public health intervention programs including HIV and AIDS, malaria, tuberculosis and, child and maternal health. They can be used in the implementation of interventions that seek to promote early diagnosis and treatment; help educate the population on the importance of disease prevention and correct management; help educate patients on the prevention of HIV; address some of the myths surrounding HIV and AIDS as well as condom use. Drug store personnel are therefore a good target for the capacity building of health care personnel and are convenient sites for recruiting patients for community education programs. By developing the human resource personnel at the drug store level, many patients' treatment outcomes will be improved.

\section{Acknowledgements}

This article is made possible by the support of the American People through the United States Agency for International Development (USAID). (Grant No. 621-A00-08-00067-00). The contents of this article are the sole responsibility of the authors and do not necessarily reflect the views of USAID, the United States Government or Howard University.

\section{REFERENCES}

[1] P. A. Bourne, "Impact of Poverty, Not Seeking Medical Care, Unemployment, Inflation, Self-Reported Illness, and Health Insurance on Mortality in Jamaica," North American Journal of Medical Sciences, Vol. 1, No. 3, 2009, p. 99.

[2] S. M. Ahmed, "Exploring Health-Seeking Behaviour of Disadvantaged Populations in Rural Bangladesh," Karolinska University Press, Stockholm, 2005. http://www.bracresearch.org/publications/thesis_masudbh ai.pdf 
[3] A. Grover, R. Kumar and S. K. Jindal, "Socio-Demographic Determinants of Treatment-Seeking Behavior among Chest Symptomatics," Indian Journal of Community Medicine, Vol. 31, No. 3, 2006, pp. 145-149.

[4] E. M. Malik, K. Hanafi, S. H. Ali, E. S. Ahmed and K. A. Mohamed, "Treatment-Seeking Behaviour for Malaria in Children under Five Years of Age: Implication for Home Management in Rural Areas with High Seasonal Transmission in Sudan," Malaria Journal, Vol. 5, No. 1, 2006, p. 60. http://www.malariajournal.com/content $/ 5 / 1 / 60$

[5] T. M. Ola, F. O. Aladekomo and B. A. Oludare, "Determinants of the Choice of Treatment Outlets for Infertility in Southwest Nigeria," Rawal Medical Journal, Vol. 33, No. 2, 2008, pp. 193-196. http://www.scopemed.org/?jft=27\&ft=27-1304694550

[6] Z. Abdu, Z. Mohammed, I. Bashier and B. Eriksson, "The Impact of User Fee Exemption on Service Utilization and Treatment Seeking Behaviour: The Case of Malaria in Sudan," The International Journal of Health Planning and Management, Vol. 19, No. S1, 2004, pp. S95-S106.

[7] World Health Organization, "Countries," 2012. http://www.who.int/countries/en/

[8] J. Chuma and C. Molyneux, "Treatment-Seeking Behaviour, Cost Burdens and Coping Strategies among Rural and Urban Households in Coastal Kenya: An Equity Analysis," Tropical Medicine \& International Health, Vol. 12, No. 5, 2007, pp. 673-686.

[9] S. Hausmann-Muela, J. M. Ribera and I. Nyamongo, "Health-Seeking Behaviour and the Health System Response," DCPP Working Paper No. 14, 2012. http://www.dcp2.org/file/29/wp14.pdf

[10] M. P. O'Donnell, "Definition of Health Promotion," American Journal of Health Promotion, Vol. 1, No. 1, 2009, pp. 4-5.

[11] I. P. Chudi, "Healthcare Problems in Developing Countries," Medical Practice and Reviews, Vol. 1, No. 1, 2010, pp. 9-11.

[12] World Health Organization, "Disease Incidence, Prevalence and Disability,” 2012.

http://www.who.int/healthinfo/global_burden_disease/20 04_report_update/en/index.html

[13] AVERT, "Sub-Saharan Africa HIV \& AIDS Statistics," 2012. http://www.avert.org/africa-hiv-aids-statistics.html

[14] A. R. Maddison and W. F. Schlech, "Will Universal Access to Antiretroviral Therapy Ever Be Possible? The Health Care Worker Challenge," Canadian Journal of Infectious Diseases \& Medical Microbiology, Vol. 21, No. 1, 2010, pp. 64-69.

http:/www.ncbi.nlm.nih.gov/pmc/articles/PMC2852293/ pdf/idmm21e064.pdf

[15] HPTN Press, "Initiation of Antiretroviral Treatment Protects Uninfected Sexual Partners from HIV Infection (HPTN Study 052)," 2012. http://www.hptn.org/web\%20documents/PressReleases/H PTN052PressReleaseFINAL5_12_118am.pdf

[16] Y. Abaynew, A. Deribew and K. Deribe, "Factors Associated with Late Presentation to HIV/AIDS Care in South Wollo ZoneEthiopia: A Case-Control Study," AIDS Re- search and Therapy, Vol. 8, No. 1, 2011, p. 8. http://www.biomedcentral.com/content/pdf/1742-6405-88.pdf

[17] R. King and H. Fomundam, "Remodeling Pharmaceutical Care in Sub-Saharan Africa (SSA) Amidst Human Resources Challenges and the HIV/AIDS Pandemic," The International Journal of Health Planning and Management, Vol. 25, No. 1, 2010, pp. 30-48. doi:10.1002/hpm.982

[18] Kenya National Bureau of Statistics (KNBS) and ICF Macro, "Kenya Demographic and Health Survey 200809," KNBS Nairobi, and ICF Macro, Maryland, 2009.

[19] World Health Organization, "The Top 10 Causes of Death," 2012.

http://www.who.int/mediacentre/factsheets/fs310/en/inde x.html

[20] J. E. Macfarlane and M. P. Alpers, "Treatment-Seeking Behaviour among the Nasioi People of Bougainville: Choosing between Traditional and Western Medicine," Ethnicity \& Health, Vol. 14, No. 2, 2009, pp. 147-168. http://www.informaworld.com/smpp/516690265-786151 $92 /$ title $\sim \mathrm{db}=$ all $\sim$ content $=\mathrm{t} 713421971 \sim \mathrm{tab}=$ issueslist $\sim$ bran ches $=14-\mathrm{v} 1414$

[21] L. Matowe, M. Duwiejua and P. Norris, "Is There a Solution to the Pharmacist Brain Drain from Poor to Rich Countries?" Pharmaceutical Journal, Vol. 272, No. 7283, 2004, pp. 98-99.

[22] D. R. Katerere and L. Matowe, "Effect of Pharmacist Emigration on Pharmaceutical Services in Southern Africa," American Journal of Health-System Pharmacy, Vol. 60, No. 11, 2003, pp. 1169-1170.

[23] Ministry of Health, "Reversing the Trends: The Second National Health Sector Strategic Plan of Kenya," 2012. http://www.nacc.or.ke/attachments/article/102/NHSSP\%2 0II-2010.pdf

[24] World Health Organization, "World Health Report 2006: Working Together for Health," 2012.

http://www.who.int/whr/2006/whr06_en.pdf

[25] Africa Health Worker Observatory (AHWO), "Human Resources for Health Country Profile (Kenya)," 2012. http://www.hrh-observatory.afro.who.int/images/Docume nt_Centre/kenya_country_profile.pdf

[26] National AIDS and STI Control Programme, "AIDS in Kenya: Trends Interventions and Impact," 7th Edition, NASCOP, Nairobi, 2005.

[27] L. Tawfik and S. Kinoti, "The Impact of HIV/AIDS on Health Systems and the Health Workforce in Sub-Saharan Africa: SARA Project," United States Agency for International Development, Bureau for Africa, Washington, 2003.

[28] E. A. McCarthy, M. E. O'Brien and W. R. Rodriguez, "Training and HIV-Treatment Scale-Up: Establishing an Implementation Research Agenda," PLoS Medicine, Vol. 3, No. 7, 2006, p. e304. doi:10.1371/journal.pmed.0030304

[29] H. A. C. M. Voeten, J. M. Otido and H. B. O'Hara. "Quality of Sexually Transmitted Disease Case Management in Nairobi, Kenya: A Comparison among Different 
Types of Healthcare Facilities," Sexually Transmitted Disease, Vol. 28, No. 11, 2001, pp. 633-642. doi:10.1097/00007435-200111000-00005

[30] C. N. Morris and A. G. Ferguson, "Sexual and Treatment-Seeking Behaviour for Sexually Transmitted Infection in Long-Distance Transport Workers of East Africa," Sexually Transmitted Infections, Vol. 83, No. 3, 2007, pp. 242-245.

http://www.ncbi.nlm.nih.gov/pmc/articles/PMC2659098/ ?tool=pmcentrez

[31] S. Karlsen, L. Say, J. Souza, C. J. Hogue, D. L.Calles, A. M. Gülmezoglu and R. Raine, "The Relationship between Maternal Education and Mortality among Women Giving Birth in Health Care Institutions: Analysis of the Cross Sectional WHO Global Survey on Maternal and Perinatal Health," BMC Public Health, Vol. 11, No. 1, 2011, p. 606. doi:10.1186/1471-2458-11-606

[32] C. McAlister and T. F. Baskett, "Female Education and Maternal Mortality: A Worldwide Survey," Journal of Obstetrics and Gynaecology Canada, Vol. 28, No. 11, 2006, pp. 983-990.

http://www.sogc.org/jogc/abstracts/full/200611_womensh ealth_3.pdf
[33] A. K. Mbonye, R. Ndyomugyenyi, P. Magnussen, S. Clark and C. Chandler, "The Feasibility of Introducing Rapid Diagnostic Tests for Malaria in Drug Shops in Uganda," Malaria Journal, Vol. 9, No.1, 2010, p. 367. doi:10.1186/1475-2875-9-367

[34] J. Stanback, C. Otterness, M. Bekiita, O. Nakayiza and A. K. Mbonye, "Injected with Controversy: Sales Administration Of Injectable Contraceptives in Drug Shops in Uganda," International Perspectives on Sexual and Reproductive Health, Vol. 37, No. 1, 2011, pp. 24-29. http://www.guttmacher.org/pubs/journals/3702411.pdf

[35] E. Patouillard, K. G. Hanson and C. A. Goodman, "Retail Sector Distribution Chains for Malaria Treatment in the Developing World: A Review of the Literature," Malaria Journal, Vol. 9, No. 1, 2010, p. 50. doi:10.1186/1475-2875-9-50

[36] Y. Tawfik, J. Nsungwa-Sabitii, G. Greer, J. Owor, R. Kesande and S. Prysor-Jones, "Negotiating Improved Case Management of Childhood Illness with Formal and Informal Private Practitioners in Uganda," Tropical Medicine \& International Health, Vol. 11, No. 6, 2006, pp. 967-973. doi:10.1111/j.1365-3156.2006.01622.x 